\title{
Effects of Dietary Tea Polyphenols on Epigallocatechin Gallate, Catechin, Egg Quality and Production of Gallus domestiaus
}

\author{
Zhenzhen Fan, Liuan Li ${ }^{*}$, Mengran Qin, Zhongmou Zhang, Keyan Zhang, Qian Wang, Chunnan Wu, Yuqiang Zhang \\ and Shuaiqiang Mao \\ Tianjin Key Laboratory of Agricultural Animal Breeding and Healthy Breeding, College of Animal Science and Veterinary \\ Medicine, Tianjin Agricultural College, Tianjin 300384, China \\ *Correspondence author: anliuli2003@163.com \\ Received 01 September 2020; Accepted 15 September 2020; Published 10 December 2020
}

\begin{abstract}
Effect of dietary tea polyphenol (TP) on the content of epigallocatechin gallate (EGCG), catechin (C) in egg yolk, and impact on egg quality and production was investigated. For this purpose, 315 healthy Gallus domestiaus aged 42 weeks were selected and randomly divided into 7 groups. The experimental group added $0.02,0.05,0.09,0.14,0.19$ and $0.24 \%$ TP to the basic diet. The control group (CK) was fed basal diet. After 10, 20 and 30 days, 15 eggs were randomly selected from each group for egg quality testing, and 20 eggs were selected for EGCG and C content test in the yolk. The results showed that in the $0.24 \% \mathrm{TP}$ group, the content of EGCG in egg yolk was significantly higher than that of CK group and the $0.02,0.05,0.09$ and $0.14 \% \mathrm{TP}$ groups $(P<0.05)$, and reached the highest on the $30^{\text {th }}$ day $(19.171 \mu \mathrm{g} / \mathrm{g})$. The content of $\mathrm{C}$ in egg yolk was significantly higher than that in CK group and the 0.02, 0.05, 0.09 and $0.14 \%$ TP groups $(P<0.05)$; and reached the highest on $30^{\text {th }}$ day $(7.071$ $\mu \mathrm{g} / \mathrm{g})$. The egg weight of the $0.14 \% \mathrm{TP}$ group on the $10^{\text {th }}$ day and of the $0.19 \%$ TP group on the $20^{\text {th }}$ day were significantly lower than that of the CK group $(P<0.05)$; the egg yolk weight of $0.14 \% \mathrm{TP}$ on the $10^{\text {th }}$ and $20^{\text {th }}$ days were significantly lower than that of the CK group $(P<0.05)$. On the $30^{\text {th }}$ day, compared with the control group, the egg weight of the $0.14 \% \mathrm{TP}$ group was significantly reduced $(P<0.05)$, the egg yolk color of 0.05 and $0.14 \%$ TP groups was significantly increased $(P<$ 0.05). During the whole experiment, the egg production of $0.24 \%$ TP group was significantly higher than that of control group $(P<0.05)$. In conclusion, adding high concentrations of TP can increase the content of EGCG and C in the yolk; however, it has a certain impact on egg weight, yolk color and eggshell thickness. Adding high concentrations of TP may increase egg production. (C) 2021 Friends Science Publishers
\end{abstract}

Keywords: Catechin; Epigallocatechin gallate; Egg yolk; Egg quality; Gallus domestiaus; Tea polyphenols

\section{Introduction}

Tea polyphenol (TP) is the general term for a class of polyhydroxy phenolic compounds contained in tea, accounting for about $30 \%$ of the dry weight of tea (Wang 1981), including catechins, flavonoids, anthocyanins and phenolic acids (Wan 2003). Catechins are an important substance in TP, and accounts for about $70 \%$ of the total TP. There are 8 monomers of catechin compounds, including epigallocatechin gallate (EGCG), epigallocatechin (EGC), catechin (C), epicatechin (EC), catechin gallate (CG), gallocatechin (GC), gallocatechin gallate (GCG) and epicatechin gallate (ECG) (Lu et al. 2018). Catechin compounds have anti-microbial, anti-oxidant, anti-mutation, anti-cancer, anti-diabetic and anti-viral effects (Dorota $e t$ al. 2004; Khan and Mukhtar 2007; Sharangi 2009). EGCG is the polyphenol with the largest proportion of catechins that has the strongest activity. Studies have shown that the antioxidant activity of EGCG is 20 times that of vitamin E and 6 times that of superoxide dismutase (Huang et al. 2010).

The strong antioxidant activity of EGCG is due to the trihydroxy group (on the $\mathrm{B}$ ring $\mathrm{C} 3, \mathrm{C} 4$ and $\mathrm{C} 5$ ) and the esterified gallate (on the C ring C3) (Ahmad et al. 2014). In vitro studies have found that $\mathrm{C}$ can scavenge free radicals, remove cytotoxic hemoglobin, and show obvious antioxidant activity (Lu et al. 2011). In addition, C inhibits tumor-specific angiogenesis by regulating the production of pro-inflammatory cytokines, nitric oxide, vascular endothelial growth factor, interleukin-2, etc. (Guruvayoorappan and Kuttan 2008).

At present, many studies focus on the improvement of livestock and poultry production performance, immune function, antioxidant function, regulation of glucose and lipid metabolism, antibacterial by adding TP to the diet (Wang 2017). Adding $300 \mathrm{mg} / \mathrm{kg}$ of tea polyphenols to broiler diets can increase the activity of T-AOC in the blood of broilers

To cite this paper: Fan Z, L Li, M Qin, Z Zhang, K Zhang, Q Wang, C Wu, Y Zhang, S Mao (2021). Effects of dietary tea polyphenols on epigallocatechin gallate, catechin, egg quality and production of Gallus domestiaus. Intl J Agric Biol 25:139-145 
and improve the antioxidant properties of meat quality (Li et al. 2012). A proper concentration dietary addition of tea polyphenols can improve the production performance and carcass quality of Partridge shank Chickens, and improve the blood biochemical indicators related to fat metabolism (Xu et al. 2011). Other studies have shown that adding green tea powder to the diet can effectively promote the development of immune organs of white feather broilers, enhance the activity of antioxidant enzymes and increase the expression of immunoglobulin (Yin 2017).

However, up to now, there are few reports on the indepth study of the effect of adding TP to the diet on the enrichment of TP active components in egg yolk. Therefore, this experiment took the local breed of Gallus domestiaus laying hens, and added different levels of TP to the diet to explore its effect on the catechin compound EGCG content and $\mathrm{C}$ content in egg yolk, as well as egg quality indicators and egg production. This article aims to provide a basis for the production of TP-rich functional eggs and the optimization of dietary additives for animal husbandry.

\section{Materials and Methods}

\section{Animals and experimental design}

This study was carried out at the chicken breeding base of Tianjin Jinwa Agricultural Technology Development Co., Ltd. from October to November in 2019. 315 healthy Gallus domestiaus aged 42 weeks were randomly selected and randomly divided into 7 groups (45 chickens in each group), raised indoors on flat ground (with an activity area of $50 \mathrm{~m}^{2}$ for each group), with free eating and drinking. The control group was fed with the basal diet, the rest 6 groups were the experimental groups, with $0.02,0.05,0.09,0.14,0.19$ and $0.24 \% \mathrm{TP}$ added to the basal diet, respectively. The pre-test period of all groups was 3 days, and the formal test period was 30 days. The composition of the basic diet is shown in Table 1.

\section{Materials, regents and equipment}

Main materials, regents and equipment are listed in Table 2.

\section{Sample collection}

Around the $10^{\text {th }}, 20^{\text {th }}$ and $30^{\text {th }}$ days, 35 eggs were randomly collected from each group, 15 eggs of which were used for the determination of egg quality, and the remaining 20 eggs were used for the detection of EGCG content and C content in the eggs. Before testing, the eggs are stored at $4^{\circ} \mathrm{C}$ for later use.

\section{Egg quality index determination}

Eggshell color were measured using an eggshell color tester of the sharp end, blunt end and middle of the eggshell, and take the average value. Use an electronic balance to measure the egg weight, yolk weight, egg white weight and eggshell weight of the eggs. Egg shape index was measured using an egg shape index tester to measure the vertical and horizontal diameters of eggs, egg shape index = vertical diameter / horizontal diameter. The relative density of eggs is measured with sodium chloride aqueous solutions of different specific gravity. The higher the relative density, the fresher the eggs. Use an eggshell thickness tester to measure the thickness of the three parts of the eggshell at the sharp end, the blunt end and the middle, and take the average value. Egg yolk color was measured by the yolk colorimeter. Use the 15 egg yellow grades of the Roche yolk color fan for comparison; higher the grade, the darker the egg yolk. Haugh unit: break the egg and pour it on a glass plate, use a protein height measuring instrument, avoiding the lace to measure the middle of the thick protein layer around the yolk, and take the average of three equidistant points to be the protein height, according to the formula calculate the corresponding Haugh unit.

$$
\text { Haugh unit=100 } \log \left(\mathrm{H}-1.7 \mathrm{~W}^{0.37}+7.57\right)
$$

Note: $\mathrm{H}$ is the height of concentrated protein $(\mathrm{mm})$, and $\mathrm{W}$ is egg weight $(\mathrm{g})$.

\section{Egg production}

The egg production of each group was recorded every day, and the egg production of each group on the $10^{\text {th }}, 20^{\text {th }}$ and $30^{\text {th }}$ day was counted and the data was analyzed.

\section{Determination of EGCG and C content in egg yolk}

High performance liquid chromatography (HPLC) was used to determine the content of EGCG and $\mathrm{C}$ in egg yolk. The sample preparation was carried out according to SN/T38482014 (SN/T 3848-2014) with slight modifications. Weigh $2 \mathrm{~g}$ egg yolk sample into a $10 \mathrm{~mL}$ graduated centrifuge tube, add methanol to the volume to $10 \mathrm{~mL}$, mix well, vortex for $2 \mathrm{~min}$, sonicate for $20 \mathrm{~min}$, freeze in the refrigerator at $20^{\circ} \mathrm{C}$ for $10 \mathrm{~min}$, centrifuge at $5000 \mathrm{r} / \mathrm{min}$ for $8 \mathrm{~min}$, filter the supernatant with $0.45 \mu \mathrm{m}$ organic microporous membrane, and the filtrate is used for detection by high performance liquid chromatography. The liquid phase conditions during the determination are: Chromatographic column: C18 (4.6 $\mathrm{mm} \times 250 \mathrm{~mm}, 5 \mu \mathrm{m})$; Mobile phase: $0.1 \%$ phosphoric acid aqueous solution: Methanol $=68: 32$ $(\mathrm{V}: \mathrm{V})$; Flow rate $0.9 \mathrm{~mL} / \mathrm{min}$; Column temperature: $30^{\circ} \mathrm{C}$; Detection wavelength: $279 \mathrm{~nm}$; Injection volume: $15 \mu \mathrm{L}$.

\section{Data analysis}

The test data are all expressed as "mean \pm standard error". Using SPSS 22.0 software, one-way ANOVE analysis (Duncan'D) was used to perform multiple comparisons between means, and a significance test was performed. $P$ < 0.05 was considered significant. 
Table 1: Basic diet composition

\begin{tabular}{llll}
\hline Component & Content $(\%)$ & Component & Content $(\%)$ \\
\hline Corn & 60 & Stone powder & 4 \\
Soybean meal & 20 & Fish meal & 2.5 \\
Sorghum & 5 & Bone meal & 2.5 \\
Bran & 4 & Premix & 2 \\
\hline
\end{tabular}

Table 2: Main materials, regents and equipment

\begin{tabular}{ll}
\hline Name & Producer \\
\hline Tea polyphenols & Wuxi Century Biological Engineering Co., Ltd. (Batch No.: FP190702) \\
Epigallocatechin Gallate (EGCG) & Tianjin Xiensi Biochemical Technology Co., Ltd.(CAS No.989-5-15) \\
Catechin (C) & China Institute for Food and Drug Control (CAS No.7295-85-4) \\
Methanol (chromatographically pure) & Merck Inc., Germany \\
Phosphoric acid (analytically pure) & Tianjin Fengchuan Chemical Reagent Technology Co., Ltd. \\
Protein height meter (NFN382) & FHK Inc., Japan \\
Analytical Balances (FB223) & Shanghai Shunning Hengping Scientific Instrument Co., Ltd. \\
Multi purpose vortex mixer (VORTEX-6) & Haimen qilinbeier Instrument Manufacturing Co., Ltd. \\
Egg shell reflectivity (TSS-QCR) & Beijing Tianxiang Feiyu Technology Co., Ltd. \\
Ultrasonic cleaning machine ( SB-100D) & Ningbo Xinzhi Biological Technology Co., Ltd. \\
High performance liquid chromatograph (Agilent-1260) & Agilent Technologies Co., Ltd. \\
Column: C18 (250 mm $\times 4.6 \mathrm{~mm}, 5 \mu \mathrm{m})$ & Shimadzu-GL Sciences (Shanghai) Laboratory Supplies Co., Ltd. \\
\hline
\end{tabular}

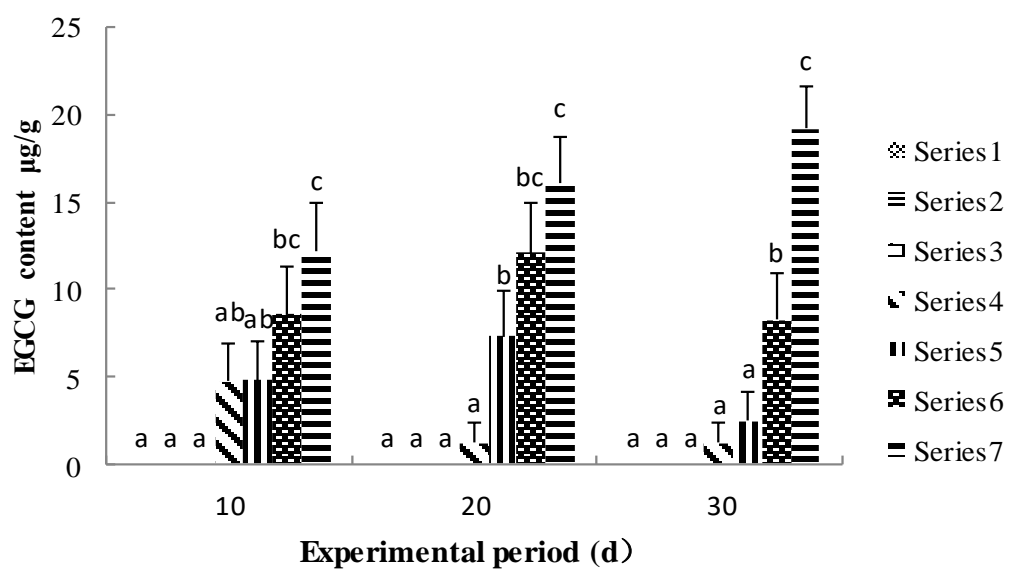

Fig. 1: Effect of adding different content of TP in diet on EGCG content in egg yolk.

Note: The lowercase letters represent the significant differences among different groups $(P<0.05)$. The same applies below

\section{Results}

\section{The effect of adding TP in diet on the content of EGCG} in egg yolk

It can be seen from Fig. 1 that the EGCG content in the egg yolk of the $0.24 \%$ TP group was significantly higher than that of the control group and the 0.02, 0.05, 0.09 and $0.14 \%$ TP groups $(P<0.05)$. And reached the highest on the $30^{\text {th }}$ day $(19.171 \mu \mathrm{g} / \mathrm{g})$, which was significantly higher than the $0.19 \%$ TP group $(P<0.05)$.

\section{The effect of adding TP in diet on C content in egg yolk}

It can be seen from Fig. 2 that the $\mathrm{C}$ content in the egg yolk of the $0.24 \%$ TP group was significantly higher than that of the CK group and the $0.02,0.05,0.09$ and $0.14 \%$ TP groups $(P<0.05)$; on the $10^{\text {th }}$ day, the $0.19 \%$ TP group was significantly higher than that in the $0.02 \%$ TP group $(P$ $<0.05$ ); on the $20^{\text {th }}$ day, the $0.19 \%$ TP group and $0.24 \%$ TP group was significantly higher than the other groups $(P<$ $0.05)$. On the $30^{\text {th }}$ day, the $0.19 \%$ TP group was significantly higher than that of the CK group and the 0.02 , 0.05 and $0.14 \% \mathrm{TP}$ groups. In addition, on the $30^{\text {th }}$ day, the $0.24 \%$ TP group reached the highest, which was 7.071 $\mu \mathrm{g} / \mathrm{g}$.

\section{The effect of adding TP in diet on egg quality}

It can be seen from Table 3 that on the $10^{\text {th }}$ day, the egg weight, yolk weight and eggshell weight of the $0.14 \% \mathrm{TP}$ group were significantly lower than that of the control group $(P<0.05)$; the egg shape index of $0.05,0.09,0.14$ and $0.24 \%$ TP groups were significantly lower than those of control group and $0.02 \%$ TP group $(P<0.05)$; the eggshell thickness of all test groups was significantly lower than the 
Fan et al. / Intl J Agric Biol, Vol 25, No 1, 2021

Table 3: Effects of different concentrations of TP on egg quality on the $10^{\text {th }}$ day

\begin{tabular}{llllllll}
\hline Egg quality Index & CK & $0.02 \% \mathrm{TP}$ & $0.05 \% \mathrm{TP}$ & $0.09 \% \mathrm{TP}$ & $0.14 \% \mathrm{TP}$ & $0.19 \% \mathrm{TP}$ & $0.24 \% \mathrm{TP}$ \\
\hline Egg weight $(\mathrm{g})$ & $54.134^{\mathrm{a}} \pm 1.512$ & $51.012^{\mathrm{ab}} \pm 0.956$ & $51.553^{\mathrm{ab}} \pm 1.080$ & $52.126^{\mathrm{ab}} \pm 1.007$ & $50.201^{\mathrm{b}} \pm 1.030$ & $51.133^{\mathrm{ab}} \pm 1.184$ & $52.066^{\mathrm{ab}} \pm 0.959$ \\
Egg yolk weight $(\mathrm{g})$ & $16.467^{\mathrm{a}} \pm 0.318$ & $16.113^{\mathrm{ab}} \pm 0.241$ & $15.842^{\mathrm{a}} \pm 0.501$ & $15.854^{\mathrm{ab}} \pm 0.294$ & $15.073^{\mathrm{b}} \pm 0.310$ & $15.673^{\mathrm{ab}} \pm 0.427$ & $15.849^{\mathrm{ab}} \pm 0.242$ \\
Egg white weight $(\mathrm{g})$ & $29.442 \pm 1.230$ & $27.470 \pm 0.654$ & $28.346 \pm 0.703$ & $29.376 \pm 0.716$ & $27.539 \pm 0.826$ & $28.239 \pm 1.208$ & $28.738 \pm 0.925$ \\
Eggshell weight $(\mathrm{g})$ & $7.052^{\mathrm{a}} \pm 0.211$ & $6.476^{\mathrm{ab}} \pm 0.178$ & $6.622^{\mathrm{ab}} \pm 0.181$ & $6.444^{\mathrm{ab}} \pm 0.207$ & $6.101^{\mathrm{b}} \pm 0.180$ & $6.680^{\mathrm{ab}} \pm 0.238$ & $6.495^{\mathrm{ab}} \pm 0.202$ \\
Eggshell color & $48.500 \pm 1.885$ & $53.371 \pm 1.396$ & $48.679 \pm 1.492$ & $50.273 \pm 1.074$ & $52.740 \pm 1.226$ & $49.814 \pm 1.802$ & $51.536 \pm 1.662$ \\
Egg Shape Index & $1.419^{\mathrm{a}} \pm 0.019$ & $1.413^{\mathrm{a}} \pm 0.015$ & $1.372^{\mathrm{b}} \pm 0.012$ & $1.343^{\mathrm{b}} \pm 0.012$ & $1.345^{\mathrm{b}} \pm 0.012$ & $1.383^{\mathrm{ab}} \pm 0.013$ & $1.353^{\mathrm{b}} \pm 0.014$ \\
Relative density $(\mathrm{g} / \mathrm{mL})$ & $1.086 \pm 0.001$ & $1.085 \pm 0.002$ & $1.086 \pm 0.002$ & $1.138 \pm 0.054$ & $1.080 \pm 0.002$ & $1.084 \pm 0.002$ & $1.084 \pm 0.001$ \\
Yolk color & $6.800 \pm 0.442$ & $7.267 \pm 0.248$ & $7.600 \pm 0.235$ & $7.333 \pm 0.270$ & $7.333 \pm 0.252$ & $7.333 \pm 0.211$ & $7.333 \pm 0.232$ \\
Haugh unit & $85.565 \pm 4.526$ & $85.066 \pm 1.646$ & $85.028 \pm 1.890$ & $89.741 \pm 1.579$ & $87.606 \pm 2.586$ & $87.748 \pm 1.742$ & $84.613 \pm 1.965$ \\
Eggshell thickness $(\mathrm{mm})$ & $0.375^{\mathrm{a}} \pm 0.005$ & $0.349^{\mathrm{b}} \pm 0.006$ & $0.349^{\mathrm{b}} \pm 0.008$ & $0.349^{\mathrm{b}} \pm 0.006$ & $0.326^{\mathrm{c}} \pm 0.005$ & $0.349^{\mathrm{b}} \pm 0.009$ & $0.353^{\mathrm{b}} \pm 0.005$ \\
\hline
\end{tabular}

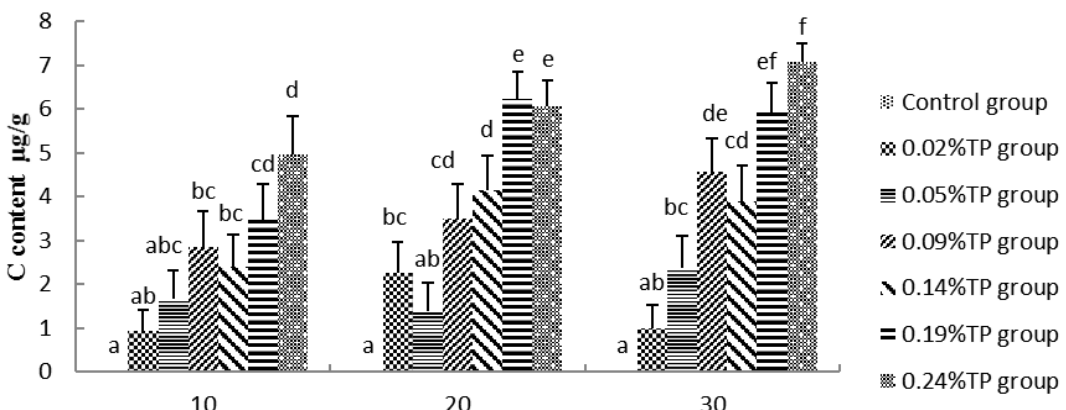

Experimental period (d)

Fig. 2: Effect of adding different content of TP in diet on $\mathrm{C}$ content in egg yolk

control group $(P<0.05)$. There were no significant differences in egg white weight, relative density, Haugh unit, egg shell color, egg yolk color and other egg quality indexes of each group of eggs $(P>0.05)$.

It can be seen from Table 4 that on the $20^{\text {th }}$ day, the egg weight of the $0.19 \%$ TP group was significantly lower than the control group $(P<0.05)$; the egg yolk weight of the $0.14 \% \mathrm{TP}$ group was significantly lower than the control group $(P<0.05)$; except for the $0.02 \%$ TP group, the eggshell color of other test groups was significantly lower than that of the control group $(P<0.05)$; the relative density of the $0.24 \%$ TP group was significantly lower than that of the 0.02 and $0.05 \%$ TP groups $(P<0.05)$; in the 0.14 and $0.24 \%$ TP groups, the eggshell thickness was significantly lower than that of the CK group $(P<0.05)$. There were no significant differences in other egg quality indicators among the groups $(P>0.05)$.

It can be seen from Table 5 that on the $30^{\text {th }}$ day, the egg weight in the $0.14 \%$ TP group was significantly lower than that in the control group, and the egg yolk color in the 0.05 and $0.14 \%$ TP groups increased significantly $(P<$ $0.05)$; the relative density of the eggs in the $0.14 \%$ TP group was significantly lower than $0.05 \%$ TP group $(P<0.05)$; the Haugh unit of $0.24 \%$ TP group was significantly lower than that of $0.14 \%$ TP group $(P<0.05) ; 0.09,0.14,0.19$ and $0.24 \%$ TP groups eggshell thickness is significantly lower than $0.05 \%$ TP group $(P<0.05)$; other egg quality indicators were not significantly different among the groups $(P>0.05)$.

\section{The effect of adding TP to the diet on egg production}

It can be seen from Fig. 3 that on the $10^{\text {th }}$ day, the egg production of the 0.05 and $0.24 \%$ TP groups was significantly higher than that of the control group, $0.14 \%$ TP, and $0.19 \%$ TP groups $(P<0.05)$; on the $20^{\text {th }}$ day, the egg production of the $0.24 \%$ TP group Significantly higher than the control group, $0.09 \%$ TP, $0.14 \%$ TP groups; on the $30^{\text {th }}$ day, the egg production of $0.02,0.05,0.19,0.24 \mathrm{TP}$ group was significantly higher than that of the control group, 0.09, 0.14\% TP groups $(P<0.05)$.

\section{Discussion}

Related studies have shown that dietary special substances may have effect on the physiology of laying hens (Celebi 2019; Demir and Kaya 2020), and thus also may effect the quality and the nutritional components of eggs (Wahab et al. 2019; Aydin and Bolukbasi 2020; Liu et al. 2020; Mahfuz et al. 2020). TP can improve health of the body, so it is widely used in livestock and poultry feed. Studies have shown that EGCG can inhibit the body's oxidative stress and inflammation, lower blood lipids and blood sugar, and regulate gene expression and related signal pathways (Masuda et al. 2001; Khan et al. 2006; Wolfram et al. 2006; Bose et al. 2008; Tipoe et al. 2010). In addition, EGCG stimulates the production of tumor necrosis factor (TNF- $\alpha$ ) and interferon (IFN- $\gamma$ ) by changing the immune response of macrophages, thereby increasing the immune activity of 
Table 4: Effects of different concentrations of TP on egg quality on the 20th day

\begin{tabular}{llllllll}
\hline Egg quality index & CK & $0.02 \% \mathrm{TP}$ & $0.05 \% \mathrm{TP}$ & $0.09 \% \mathrm{TP}$ & $0.14 \% \mathrm{TP}$ & $0.19 \% \mathrm{TP}$ & $0.24 \% \mathrm{TP}$ \\
\hline Egg weight $(\mathrm{g})$ & $54.295^{\mathrm{a}} \pm 0.769$ & $50.764^{\mathrm{ab}} \pm 1.067$ & $52.174^{\mathrm{ab}} \pm 0.993$ & $51.462^{\mathrm{ab}} \pm 1.028$ & $51.555^{\mathrm{ab}} \pm 1.389$ & $50.165^{\mathrm{b}} \pm 1.080$ & $52.397^{\mathrm{ab}} \pm 1.136$ \\
Egg yolk weight $(\mathrm{g})$ & $16.950^{\mathrm{a}} \pm 0.304$ & $16.125^{\mathrm{ab}} \pm 0.365$ & $15.900^{\mathrm{ab}} \pm 0.224$ & $15.990^{\mathrm{ab}} \pm 0.240$ & $15.671^{\mathrm{b}} \pm 0.412$ & $16.195^{\mathrm{ab}} \pm 0.532$ & $16.337^{\mathrm{ab}} \pm 0.391$ \\
Egg white weight $(\mathrm{g})$ & $29.931 \pm 0.841$ & $27.289 \pm 0.795$ & $28.705 \pm 0.712$ & $28.257 \pm 0.798$ & $29.853 \pm 1.232$ & $27.481 \pm 0.824$ & $28.800 \pm 1.137$ \\
Eggshell weight $(\mathrm{g})$ & $6.674 \pm 0.233$ & $6.600 \pm 0.176$ & $6.859 \pm 0.154$ & $6.599 \pm 0.149$ & $6.720 \pm 0.225$ & $6.414 \pm 0.137$ & $6.686 \pm 0.277$ \\
Eggshell color & $55.260^{\mathrm{a}} \pm 1.689$ & $51.340^{\mathrm{ab}} \pm 1.336$ & $46.907^{\mathrm{b}} \pm 1.748$ & $49.973^{\mathrm{b}} \pm 1.196$ & $49.893^{\mathrm{b}} \pm 0.989$ & $50.087^{\mathrm{b}} \pm 1.676$ & $49.807^{\mathrm{b}} \pm 2.181$ \\
Egg Shape Index & $1.374 \pm 0.015$ & $1.395 \pm 0.016$ & $1.391 \pm 0.016$ & $1.365 \pm 0.016$ & $1.382 \pm 0.014$ & $1.381 \pm 0.012$ & $1.376 \pm 0.010$ \\
Relative density $(\mathrm{g} / \mathrm{mL})$ & $1.084^{\mathrm{ab}} \pm 0.003$ & $1.090^{\mathrm{a}} \pm 0.002$ & $1.090^{\mathrm{a}} \pm 0.002$ & $1.089^{\mathrm{ab}} \pm 0.002$ & $1.085^{\mathrm{ab}} \pm 0.002$ & $1.087^{\mathrm{ab}} \pm 0.002$ & $1.082^{\mathrm{b}} \pm 0.003$ \\
Yolk color & $7.300 \pm 0.213$ & $7.333 \pm 0.159$ & $7.143 \pm 0.143$ & $7.400 \pm 0.254$ & $7.267 \pm 0.228$ & $7.267 \pm 0.206$ & $7.000 \pm 0.138$ \\
Haugh unit & $82.640 \pm 3.410$ & $83.572 \pm 2.988$ & $81.247 \pm 1.994$ & $82.374 \pm 3.446$ & $85.288 \pm 1.402$ & $83.431 \pm 1.960$ & $83.646 \pm 2.362$ \\
Eggshell thickness $(\mathrm{mm})$ & $0.371^{\mathrm{a}} \pm 0.007$ & $0.364^{\mathrm{ab}} \pm 0.007$ & $0.362^{\mathrm{ab}} \pm 0.006$ & $0.365^{\mathrm{ab}} \pm 0.007$ & $0.341^{\mathrm{bc}} \pm 0.006$ & $0.356^{\mathrm{ab}} \pm 0.007$ & $0.333^{\mathrm{c}} \pm 0.011$ \\
\hline
\end{tabular}

Table 5: Effects of different concentrations of TP on egg quality on the 30th day

\begin{tabular}{llllllll}
\hline Egg quality index & $\mathrm{CK}$ & $0.02 \% \mathrm{TP}$ & $0.05 \% \mathrm{TP}$ & $0.09 \% \mathrm{TP}$ & $0.14 \% \mathrm{TP}$ & $0.19 \% \mathrm{TP}$ & $0.24 \% \mathrm{TP}$ \\
\hline Egg weight $(\mathrm{g})$ & $54.058^{\mathrm{a}} \pm 0.882$ & $51.419^{\mathrm{ab}} \pm 1.272$ & $52.170^{\mathrm{ab}} \pm 0.821$ & $50.788^{\mathrm{ab}} \pm 1.174$ & $49.913^{\mathrm{b}} \pm 1.008$ & $51.717^{\mathrm{ab}} \pm 1.217$ & $51.608^{\mathrm{ab}} \pm 0.608$ \\
Egg yolk weight $(\mathrm{g})$ & $17.141 \pm 0.219$ & $16.332 \pm 0.359$ & $16.304 \pm 0.401$ & $16.163 \pm 0.341$ & $16.026 \pm 0.319$ & $16.267 \pm 0.395$ & $16.131 \pm 0.361$ \\
Egg white weight $(\mathrm{g})$ & $30.598 \pm 0.872$ & $27.786 \pm 0.916$ & $28.245 \pm 0.384$ & $27.901 \pm 0.998$ & $27.828 \pm 1.003$ & $27.981 \pm 0.967$ & $28.552 \pm 1.110$ \\
Eggshell weight $(\mathrm{g})$ & $30.598 \pm 0.872$ & $27.786 \pm 0.916$ & $28.245 \pm 0.384$ & $27.901 \pm 0.998$ & $27.828 \pm 1.003$ & $27.981 \pm 0.967$ & $28.552 \pm 1.110$ \\
Eggshell color & $51.260 \pm 1.721$ & $49.467 \pm 1.811$ & $48.547 \pm 1.865$ & $51.247 \pm 1.295$ & $50.680 \pm 1.799$ & $50.073 \pm 1.678$ & $48.414 \pm 1.565$ \\
Egg Shape Index & $1.381 \pm 0.020$ & $1.399 \pm 0.011$ & $1.387 \pm 0.013$ & $1.376 \pm 0.016$ & $1.373 \pm 0.013$ & $1.383 \pm 0.013$ & $1.367 \pm 0.013$ \\
Relative density $(\mathrm{g} / \mathrm{mL})$ & $1.081^{\mathrm{ab}} \pm 0.001$ & $1.085^{\mathrm{ab}} \pm 0.002$ & $1.086^{\mathrm{a}} \pm 0.002$ & $1.082^{\mathrm{ab}} \pm 0.001$ & $1.080^{\mathrm{b}} \pm 0.002$ & $1.081^{\mathrm{ab}} \pm 0.002$ & $1.081^{\mathrm{ab}} \pm 0.002$ \\
Yolk color & $6.933^{\mathrm{c}} \pm 0.153$ & $7.286^{\mathrm{abc}} \pm 0.163$ & $7.867^{\mathrm{a}} \pm 0.192$ & $7.333^{\mathrm{abc}} \pm 0.187$ & $7.600^{\mathrm{ab}} \pm 0.254$ & $7.067^{\mathrm{bc}} \pm 0.228$ & $7.091^{\mathrm{bc}} \pm 0.211$ \\
Haugh unit & $70.898^{\mathrm{ab}} \pm 2.460$ & $69.974^{\mathrm{ab}} \pm 2.180$ & $73.249^{\mathrm{ab}} \pm 2.108$ & $73.062^{\mathrm{ab}} \pm 2.199$ & $74.646^{\mathrm{a}} \pm 1.865$ & $69.715^{\mathrm{ab}} \pm 3.229$ & $66.692^{\mathrm{b}} \pm 2.678$ \\
Eggshell thickness $(\mathrm{mm})$ & $0.349^{\mathrm{abc}} \pm 0.006$ & $0.363^{\mathrm{ab}} \pm 0.008$ & $0.370^{\mathrm{a}} \pm 0.007$ & $0.335^{\mathrm{c}} \pm 0.005$ & $0.329^{\mathrm{c}} \pm 0.007$ & $0.343^{\mathrm{bc}} \pm 0.009$ & $0.345^{\mathrm{bc}} \pm 0.010$ \\
\hline
\end{tabular}

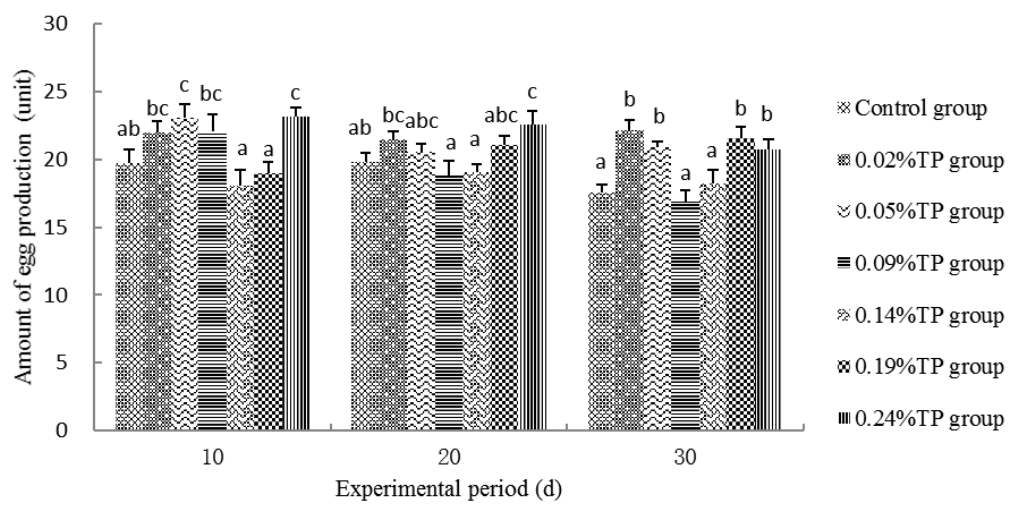

Fig. 3: Effect of adding different content of TP in diet on egg production

macrophages and achieving the purpose of suppressing tumors (Matsunaga et al. 2001).

Compared with EGCG, C occupies a smaller proportion in $\mathrm{TP}$, and its antioxidant and anti-inflammatory activities have been confirmed in some studies (Moraeset al. 2014). However, there is no report on the analysis of TP composition in eggs by adding $\mathrm{TP}$ to the diet. In this experiment, Gallus domestiaus was used as the experimental animal to study the effect of dietary supplementation of TP on the content of EGCG and $\mathrm{C}$ in eggs. The results showed that the content of EGCG in egg yolk increased with the increase of TP.

On the $30^{\text {th }}$ day, the content of EGCG in egg yolk of $0.24 \%$ TP group was significantly higher than that of control group and other experimental groups. On the $30^{\text {th }}$ day, the content of EGCG in egg yolk of $0.24 \%$ TP group was the highest, reaching $19.171 \mu \mathrm{g} / \mathrm{g}$. On the $10^{\text {th }}, 20^{\text {th }}$ and $30^{\text {th }}$ day, the content of $\mathrm{C}$ in yolk of $0.24 \%$ TP group was significantly higher than that of control group and 0.02 , $0.05,0.09$ and $0.14 \%$ TP groups. On the $30^{\text {th }}$ day, the C content in yolk of $0.24 \%$ TP group was the highest, reaching $7.071 \mu \mathrm{g} / \mathrm{g}$. Comprehensive analysis suggests that the content of EGCG and $\mathrm{C}$ in egg yolk increases with the increase of dietary TP. Adding a higher concentration of TP can significantly increase the enrichment of EGCG and $\mathrm{C}$ in egg yolk. The results of this study provide a theoretical and practical basis for the development of TP rich functional eggs.

Egg weight is an important indicator for evaluating egg grade. Egg weight is affected by the type of layer, the composition of the diet, the age of the layer, the breeding environment and other conditions. Wang xiaohong and other studies have shown that dietary supplementation of $400 \mathrm{mg} / \mathrm{kg}$ TP can significantly reduce the average egg 
weight in the first 4 weeks of the test period (Wang et al. 2017). Other studies have shown that dietary supplementation of catechins can increase the fertilization rate and hatchability of quail and prolong the shelf life of eggs, but it reduces egg weight and egg shell quality (Kara et al. 2016). The results of this test show that during the entire test period, compared with the control group, the egg weight of each test group has a tendency to decrease, which is basically consistent with the above research results. The analysis may be due to the anti-nutrients factors such as phenolic acid and caffeine contained in TP that can destroy or hinder the digestion and absorption of certain nutrients in laying hens; or catechins inhibit the intestinal absorption of fat and the activity of fat synthase, affect the formation of egg yolk lipids, thereby reducing egg weight (Yamane et al. 1999; Kojlma and Yoshida 2008).

The color of egg yolk is also an important sensory index for evaluating egg quality, it mainly depends on the type and quantity of carotenoids obtained by the laying hens from the diet. In this experiment, on the $10^{\text {th }}$ day, the egg yolk color of each test group was higher than that of the control group. On the $30^{\text {th }}$ day, compared with the control group, the egg yolk color of the 0.05 and $0.14 \%$ TP groups were significantly increased by 13.47 and $9.62 \%$, respectively. The results indicate that adding TP to the diet of laying hens can improve the color of egg yolk, and the specific mechanism remains to be further studied.

The thickness of the eggshell is generally $0.3 \sim 0.4 \mathrm{~mm}$. If the eggshell is too thin, it will affect the storage, transportation and sales of the egg; if the eggshell is too thick, the hatching rate of the laying hen will be reduced (Zhao et al. 2017). During the experiment, the eggshell thickness of each experimental group was $0.3 \sim 0.4 \mathrm{~mm}$. On the $10^{\text {th }}$ day, the eggshell thickness of each test group was significantly lower than that of the control group. On the $20^{\text {th }}$ day, the eggshell thickness of the $0.14 \%$ TP group and $0.24 \%$ TP group was significantly lower than that of the control group. The analysis may be due to the caffeine contained in TP. Studies have shown that the intake of caffeine in the body will lead to the decrease of calcium absorption and loss of calcium in the digestive tract, and reduce bone mineral density (Tsuang et al. 2006), which will reduce the thickness of the eggshell and affect the quality of the eggshell.

Egg production is one of the important economic traits of laying hens. Studies have shown that when the Roman layer is 30 weeks old, adding $6000 \mathrm{mg} / \mathrm{kg}$ of green tea powder and $1000 \mathrm{mg} / \mathrm{kg}$ of TP to the diet can significantly increase the egg production rate of the layer (Xiao 2010). Because TP has anti-oxidant and antibacterial properties, scavenge free radicals, and improve the intestinal microbial environment. It can improve absorption and utilization of nutrients in the diet, thereby increasing feed conversion rate and egg production. The results of this test showed that during the entire test period, the egg production of the $0.24 \%$ TP group was significantly higher than that of the control group, and the egg production of other test groups also tended to be higher than that of the control group. The experimental results are similar to the above result, which is, adding higher concentration of TP can improve the egg production of laying hens.

\section{Conclusion}

Adding a certain amount of TP to the diet can significantly increase the content of EGCG and C in the yolk, which has a certain impact on the egg weight, yolk color, and eggshell thickness. Adding high concentrations of TP can increase egg production.

\section{Acknowledgment}

We acknowledge the financial supports of Tianjin Enterprise Technology Commissioner Project (19JCTPJC59500); the Major Special Scientific and Technological Project and Engineering Project of Tianjin (18ZXBFNC00310) and the "131" Innovative Talent Team Building Project of Tianjin (20180318).

\section{Author Contributions}

LA Li designed this study; ZZ Fan, MR Qin, ZM Zhang, KY Zhang and Q Wang conducted the experiments; ZZ Fan, $\mathrm{CN} \mathrm{Wu}, \mathrm{YQ}$ Zhang and SQ Mao analyzed the main data; ZZ Fan and LA Li wrote the manuscript.

\section{References}

Ahmad RS, MS Butt, N Huma, MT Sultan, MU Arshad, Z Mushtaq, F Saeed (2014). Quantitative and qualitative portrait of green tea gatechins (Gtc) through Hplc. Intl J Food Propert 17:1626-1636

Aydin A, SC Bolukbasi (2020). Effect of supplementation of hen diet with pennyroyal extract (Mentha pulegium) on performance, egg quality and yolk TBARS values. Pak J Zool 52:1045-1051

Bose M, JD Lambert, J Ju, KR Reuhl, SA Shapses, CSYang (2008). The major green tea polyphenol, (-)-epigallocatechin-3-gallate, inhibits obesity, metabolic syndrome, and fatty liver disease in high-fat-fed mice. J Nutr 138:1677-1683

Celebi S (2019). Effect of dietary vitamin E, selenium and their combination on concentration of selenium, MDA, and antioxidant enzyme activities in some tissues of laying hens. Pak J Zool 51:1155-1161

Demir Z, H Kaya (2020). Effect of bee pollen supplemented diet on performance, egg quality traits and some serum parameters of laying hens. Pak J Zool 52:549-555

Dorota M, M Sabine, E Ibrahim (2004). The effect of ascorbic acid on total antioxidant activity of black and green teas. Food Chem 88:447-451

Guruvayoorappan C, G Kuttan (2008). (+)-Catechin inhibits tumour angiogenesis and regulates the production of nitric oxide and TNF- $\alpha$ in LPS-stimulated macrophages. Innate Immun 14:160-174

Huang W, L Ding, Q Huang (2010). Carbonyl Reductase 1 as a Novel Target of (-)-epigallocatechin gallate against hepatocellular carcinoma. Hepatology 52:703-714

Kara K, BK Güçlü, M Şentürk, Y Konca (2016). Influence of catechin (flavan-3-ol) addition to breeder quail (Coturnix coturnix japonica) diets on productivity, reproductive performance, egg quality and yolk oxidative stability. J Appl Anim Res 44:436-441 
Khan N, H Mukhtar (2007). Tea polyphenols for health promotion. Life Sci 81:519-533

Khan N, F Afaq, M Saleem, N Ahmad, H Mukhtar (2006). Targeting multiple signalling pathways by green tea polyphenol (-)epigallocatechin-3-gallate. Cancer Res 66:2500-2505

Kojlma S, Y Yoshida (2008). Effects of green tea powder feed supplement on performance of hens in the late stage of laying. Intl J Poult Sci 7:491-496

Li L, YN Min, W Zhang, FZ Liu, ZY Niu, J Zhang, J Wang, JJ Wang, SK Liu, HL Li (2012). Effects of dietary tea polyphenols on growth performance and antioxidant activity in broilers fed with high levels of DDGS diets. Anim Husb Vet Med 44:17-22

Liu H, QF Yu, XP Tang, CK Fang, SJ Chen, RJ Fang (2020). Effect of selenium on performance egg quality egg selenium content and serum antioxidant capacity in laying hens. Pak J Zool 52:635-640

Lu CQ, SH Mao, HR Tong, YP Ding (2018). Progress in the synthesis of catechin and its derivatives. Food Sci 39:316-326

Lu NH, PQ Chen, Y Qin, YP Yi (2011). Anti- and pro-oxidant effects of (+)-catechin on hemoglobin-induced protein oxidative damage. Toxicol In vitro 25:833-838

Masuda M, M Suzui, I B Weinstein (2001). Effects of epigallocatechin-3gallate on growth, epidermal growth factor receptor signalling pathways, gene expression, and chemosensitivity in human head and neck squamous cell carcinoma cell lines. Clin Cancer Res 7:4220 4229

Mahfuz S, SY Wang, M Chen, F Zao, D Zhen, ZJ Liu, H Song (2020). Effects of mushroom stem waste (Flammulina velutipes) on laying performance, egg quality and serum biochemical indices. Pak $J$ Zool 52:255-262

Matsunaga K, TW Klein, H Friedman, Y Yamamoto (2001). Legionella pneumophila replication in macrophages inhibited by selective immunomodulatory effects on cytokine formation by epigallocatechin gallate, a major form of tea catechins. Infect Immun 69:3947-3953

Moraes CMBD, S Bitencourt, FCD Mesquita, D Mello, LPD Oliveira, GVD Silva, V Lorini, E Caberlon, BD Souza Basso, J Schmid, GA Ferreira, JRD Oliveira (2014). (+)-Catechin attenuates activation of hepatic stellate cells. Cell Biol Intl 38:526-530

Sharangi AB (2009). Medicinal and therapeutic potentialities of tea (Camellia sinensis L.) - A review. Food Res Intl 42:529-535
Tipoe GL, TM Leung, EC Liong, TYH Lau, ML Fung, AA Nanji (2010). Epigallocatechin-3-gallate (EGCG) reduces liver inflammation, oxidative stress and fibrosis in carbon tetrachloride (CCl4)-induced liver injury in mice. Toxicology 273:45-52

Tsuang YH, JS Sun, LT Chen, SCK Sun, SC Chen (2006). Direct effects of caffeine on osteoblastic cells metabolism: the possible causal effect of caffeine on the formation of osteoporosis. J Orthop Surg Res 1:110

Wahab F, N Chand, RU Khan, N Ahmad, U Parvez, ZU Rehman, S Naz (2019). Dietary supplementation of fenugreek (Trigonella foenum graecum) on the egg quality characteristics of Rhode Island red spent layers. Pak J Zool 51:1793-1797

Wan XC (2003). Biochemistry of Tea, $3^{\text {rd }}$ edn. China Agriculture Press, BeiJing, China

Wang XH (2017). Tolerance and Validity Research About Tea Polyphenols on Laying Hens. M.Sc. Thesis. Chinese Academy of Agricultural Sciences Dissertation, Beijing, China

Wang XH, SG Wu, YM Cui, GH Qi, J Wang, HJ Zhang (2017). Effects of tea polyphenols on the production performance, egg quality and antioxidant capacity of laying hens. Chin J Anim Nutr 29:193-201

Wang ZN (1981). Biochemical Principle of Tea. Agricultural Press, Beijing, China

Wolfram S, D Raederstorff, M Preller, Y Wang, SR Teixeira, C Riegger, P Weber (2006). Epigallocatechin gallate supplementation alleviates diabetes in rodents. J Nutr 136:2512-2518

Xiao H (2010). Effects of green tea and tea polyphenols on the meat qualities, egg characteristic and laying performance of Lohamann hens. M.Sc. Thesis. Anhui Agricultural University, Anhui, China

Xu XJ, HY Cai, L Zhang, LW Wang, W Chen (2011). Effects of tea polyphenols added in diets on growth performance, carcass quality and serum lipid in broilers. Chin Feed 10:30-40

Yamane T, H Goto, D Takahashi, H Takeda, K Otomaki, T Tsuchida (1999). Effects of hot water extracts of tea on performance of laying hens. Jpn Poult Sci 36:31-37

Yin CN (2017). Effect of dietary supplemented green tea on humoral immune response of broilers. M.Sc. Thesis. Anhui Agricultural University, Anhui, China

Zhao GX, D Liu, L Wang, J Tang, X Zhang (2017). Influencing factors and controlling measures of egg quality in late stage of egg production. Feed Industr 38:1-6 